\title{
Publisher Correction: Climate change threatens the world's marine protected areas
}

John F. Bruno (D), Amanda E. Bates (1D, Chris Cacciapaglia, Elizabeth P. Pike, Steven C. Amstrup, Ruben van Hooidonk (D), Stephanie A. Henson and Richard B. Aronson

Correction to: Nature Climate Change https://doi.org/10.1038/s41558-018-0149-2, published online 7 May 2018.

In the version of this Letter originally published, the $x$ axes titles of Fig. 3 erroneously read 'Latitude'; they should have read 'Longitude'. This has been corrected in the online versions of the Letter.
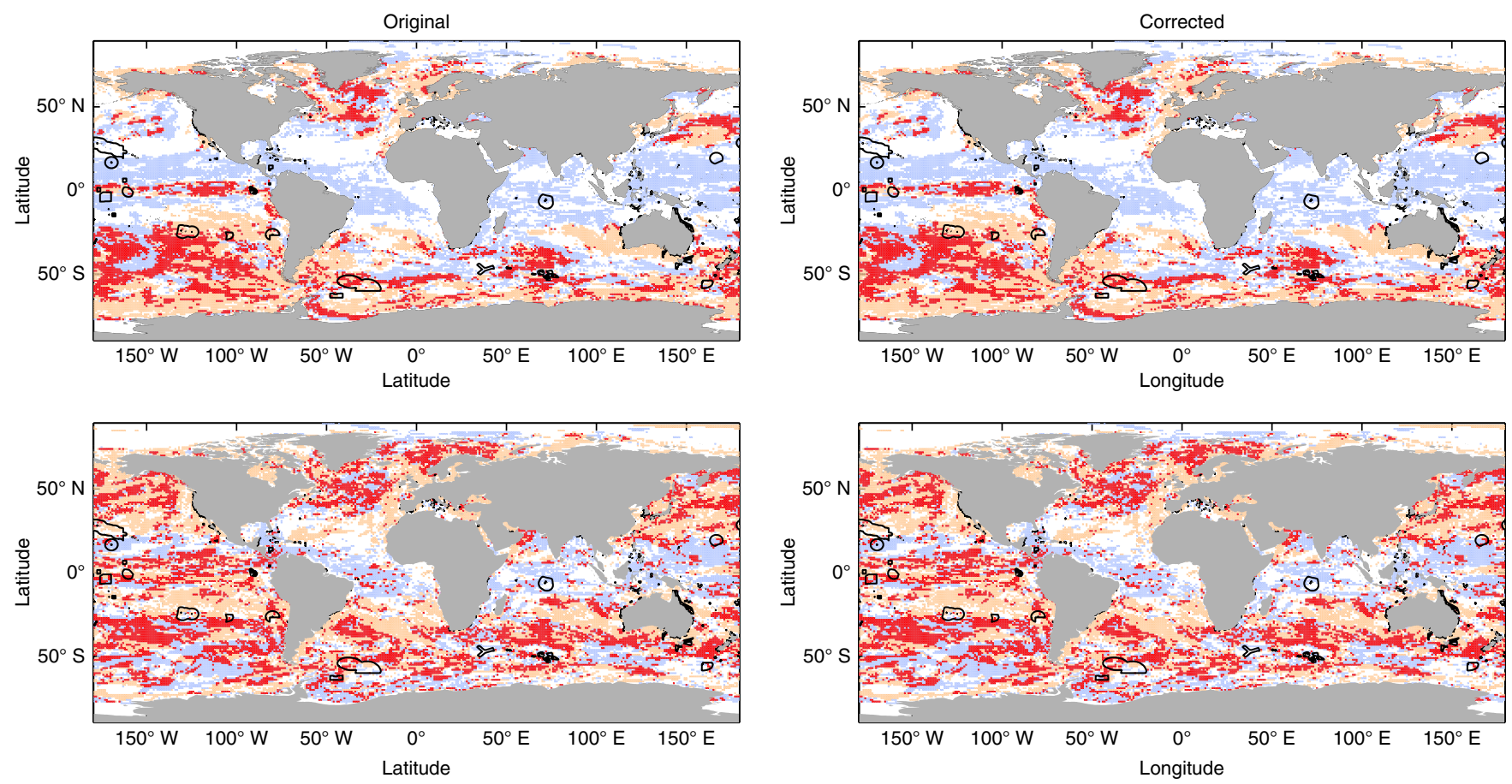

Fig. 3 | Original and corrected.

Published online: 23 May 2018

https://doi.org/10.1038/s41558-018-0202-1 